\title{
Zika virus, an emerging flavivirus, as a cause of fever and rash in a traveller returning from Central America
}

\author{
Teale $\mathrm{A}^{1}$, Payne $\mathrm{M}^{2,3}$, England $\mathrm{J}^{1}$, Morshed $\mathrm{M}^{4}$, Hull $\mathrm{M}^{1,5 *}$
}

\begin{abstract}
Fever in a returning traveller is a common clinical scenario for physicians in primary and acute care. Differential diagnoses for these patients are generated based on presenting clinical symptoms, travel destinations, potential exposure activities as well as the incubation period of common etiologic agents. In a case of fever and rash in a woman returning to Canada from El Salvador in November 2015, measles, dengue and chikungunya viral infections were queried as possible causes. Subsequent molecular testing using amplification of conserved regions of the flavivirus genome from nasopharyngeal and urine samples was positive, suggesting an active flavivirus infection. Sequencing was significant for the identification of Zika virus, a flavivirus that has only recently become endemic to Brazil and is now emerging throughout Central America. Zika virus should now be included in the differential diagnosis for travellers returning from Central and South America with a febrile illness and rash. To our knowledge this is the first reported case of Zika virus in Canada related to the most recent outbreak in Central America, South America and the Caribbean.
\end{abstract}

Suggested citation: Teale A, Payne M, England J, Morshed M, Hull M. Zika virus, an emerging flavivirus, as a cause of fever and rash in a traveller returning from Central America. Can Comm Dis Rep 2016;42:68-71. https://doi.org/10.14745/ccdr.v42i03a04

\section{Introduction}

Zika virus is an emerging arthropod-borne member of the flavivirus genus that is closely related to other medically significant viruses including dengue, Japanese encephalitis virus, West Nile virus and yellow fever virus (1). Initially isolated from the Zika Forest in Uganda in 1947 (2), epidemiological surveys have shown evidence of serologic exposure in African countries including Gabon, Nigeria, Central African Republic and Sierra Leone (3-6) as well as in Southeast Asia, notably Indonesia, Malaysia and Thailand (7-10). Mosquitoes from the Aedes genus have been implicated as the primary vector of transmission of Zika virus (11). Recent outbreaks have occurred in several island nations in the South Pacific Ocean including Micronesia in 2007 (12), as well as French Polynesia, New Caledonia and the Cook Islands in 2013 and 2014 (13). Cases of Zika virus infection were first identified in the Americas in Brazil in 2014, and autochthonous transmission has been seen in northeastern regions of that country (14-15). As of December 2015, cases have been reported in other countries of Latin America including Venezuela, Suriname, Paraguay, Panama, Guatemala, Mexico, Colombia and El Salvador (16).

\section{Case}

A 52-year-old woman whose past medical history was significant for Parkinson's disease presented to the emergency department with fever and a new rash after recent travel to El Salvador.
The patient immigrated to Canada in 1992 from El Salvador. The primary purpose of her recent 14-day trip was to visit friends and relatives. She did not seek pre-travel medical advice, and her vaccination status was unclear. She stayed exclusively in San Salvador, the capital city of El Salvador. She denied any animal or fresh water exposures or any new sexual contacts. She received multiple mosquito bites during her visit. She felt well throughout her trip but noted subjective fevers along with myalgias and fatigue beginning five days after her return to Canada. She also had symptoms of conjunctivitis, but this was diminishing by presentation to the emergency room. An erythematous rash had initially developed on her face and spread to her trunk and arms the following day, which prompted the patient's presentation on day five of her illness.

On arrival, the patient was afebrile and non-toxic in appearance. Review of systems was significant for mild headache with no retro-orbital discomfort. She endorsed generalized myalgias and fatigue but no specific arthralgias. The patient denied significant respiratory or gastrointestinal symptoms. Examination was significant for a blanchable, maculopapular rash over the face that extended to the trunk, arms and upper legs. There was minimal conjunctival injection and no Koplik spots were identified. Cardiovascular and respiratory examinations were unremarkable and examination of the abdomen did not demonstrate splenomegaly.

Basic investigations collected on day five of the patient's illness were sent, including a complete blood count, which revealed mild leukopenia (3.2 x 109 cells/L; 
reference: $3.5-10.5 \times 109$ cells/L) and mild thrombocytopenia (112 x 109 cells/L; reference 150-450 x 109 cells/L). Electrolytes, liver profile and renal function tests were normal. A chest $x$-ray was normal. Thin and thick malaria smears along with a $P$. falciparum rapid antigen test were negative. Rubella serology showed evidence of past infection/immunity. A monospot test was negative. HIV serology and syphilis enzyme immunoassay (EIA) were negative. Parvovirus IgM and IgG were negative. Blood cultures were negative, as was a throat culture. A throat swab for enterovirus polymerase chain reaction (PCR) was performed, and was negative. Hepatitis A serology showed evidence of immunity through previous infection or immunization. The patient was immune through vaccination for hepatitis $B$.

Despite her age, the history of a centripetal rash raised the possibility of measles, but both a nasopharyngeal swab (NPS) and a urine sample collected for measles PCR were negative. In addition, measles lgG showed evidence of prior infection/immunity. Dengue serology was ordered, and our patient was IgG positive and IgM negative, which is compatible with a history of previous flavivirus infection. PCR testing was then performed on the urine and NPS using a pan-flavivirus PCR targeting the NS5 gene (methodology previously described (17)). Both the urine and NPS were positive, but the signal strength was 10 times stronger in the NPS sample. The 217 base pair amplicon was sequenced, with a $216 / 217$ base pair (99\%) match for Zika virus (GenBank accession no. KF993678.1).

This diagnosis of Zika virus infection was available one week after the initial infectious diseases consultation. Repeat dengue serology, two weeks after first presentation, was positive for both $\lg \mathrm{M}$ and $\lg \mathrm{G}$.

\section{Discussion}

This is the first reported case of Zika virus in Canada related to the most recent outbreak in Central America, South America and the Caribbean. Within a decade of the outbreak in Micronesia in 2007, Zika virus has been documented in several island nations in the South Pacific and, recently, in multiple countries in South and Central America. Zika virus is capable of transmission through numerous species of the Aedes genus, notably Aedes aegypti and Aedes albopictus (11). These species, which have adapted to urban and peri-urban environments, have been implicated in the rapid spread of chikungunya virus and dengue (18). Given the similarities in transmission vectors, it has been speculated that Zika virus has the potential to follow the epidemiological trends of these viruses and continue to gain footholds in Central America, the Caribbean and possibly more northern locales including parts of the southern United States (19). With ongoing transmission in Brazil and anticipated travel to the 2016

Rio de Janeiro Olympic Games, the potential for increasing incidence of imported cases in returning travellers is significant.

Clinical manifestations of Zika virus have been well characterized in previous outbreaks. The most common symptom described has been a macular or papular rash followed by subjective or measured fever (12). Of note, none of the temperatures of patients with confirmed Zika virus infection exceeded $37.9^{\circ} \mathrm{C}$ in one prior outbreak (12). Other frequently described symptoms include arthralgias, conjunctivitis, myalgias, retro-orbital pain, and edema of the extremities (12-13). Symptoms typically last 3 to 12 days and overall disease course is thought to be milder than dengue or chikungunya (13); however, severe neurological complications including Guillain-Barre Syndrome have been described (12). In addition, the current epidemic in Brazil has now been linked to an increased incidence of congenital microcephaly (20), although further study is needed to confirm this association.

Given the non-specific clinical presentation of Zika virus infection, differentiating between Zika virus, dengue and chikungunya virus is difficult. Fever, rash, myalgias, arthralgias and retro-orbital pain are common symptoms of all three viruses. It has been suggested that extremity edema as well as conjunctivitis are more common in Zika virus (13) whereas severe arthralgias and persistent joint symptoms are more commonly associated with chikungunya (18). Cytopenias and lymphadenopathy are thought to be more common in dengue and chikungunya than in Zika virus infections (13). As well, the presence of a high fever may argue against Zika virus. Overt hemorrhagic fever has not been reported in association with Zika virus infection. Co-infection of Zika and dengue or other arboviruses is a concern given the common vector and geographic distribution. Differences in symptomatic presentation and disease severity due to co-infection are not known. In this case, the patient's primary symptoms of rash and fever abated one to two weeks after the initial onset of symptoms. The patient has noted ongoing mild generalized myalgias persisting past resolution of her other symptoms.

Supportive care with analgesics and antipyretics until symptom resolution is the mainstay of Zika virus infection management. Currently no directed treatment or vaccine is available. Zika virus infection is best prevented by avoiding mosquito vectors; travellers to endemic areas should wear long-sleeved clothing, use insect repellent and stay and sleep in screened-in or air-conditioned rooms.

Diagnosis of Zika virus is challenging as standard serologic testing cross-reacts significantly with other flaviviruses (12). In particular, dengue virus may present with a similar clinical syndrome and complicate serologic interpretation. A previous case in Canada described Zika virus in a traveller returning from Thailand, where a positive IgM for dengue initially led to a false diagnosis; this was corrected when the dengue lgG was persistently negative, leading the clinical team to investigate for other flaviviruses using molecular methods (21). In our patient, an initial negative IgM and a positive IgG for dengue likely reflects a history of dengue virus infection, with testing performed too early in the disease course to detect the cross-reacting IgM. Zika virus IgM typically develops within the first week of illness, and as our patient had only been ill for five days, the lgM response may not have developed at the time of testing (22). Repeat dengue IgM completed 19 days after illness onset was positive, showing the presence of acute cross-reacting Zika virus antibodies. A secondary flavivirus infection, as we were suspecting in our case, has been shown to induce a neutralizing antibody response with a greater degree of serologic cross-reactivity against other flaviviruses, which could further complicate interpretation of serologic testing (22).

For travellers returning from areas endemic for both Zika and dengue virus, molecular methods are likely to be more helpful 
than serologic methods due to greater specificity and decreased turnaround time. The specimen recommended for Zika virus PCR is serum, during the first week after the onset of symptoms (23). Urine may be PCR positive for 10 days or longer after onset of symptoms (24). Testing from a NPS has been described, but it is unclear how long the virus will persist at this site (25). In our case, Zika virus was detected by the BCCDC Public Health Laboratory's PCR assay followed by amplicon sequencing. The sample was also sent to the National Microbiology Laboratory for confirmation. The NPS had a cycle threshold value of 27.46, a signal 10 times stronger than the urine, which had a cycle threshold value of 32.16. The results from molecular testing were also rapidly available, with the diagnosis of Zika virus made seven days after the initial assessment and specimen collection.

\section{Conclusions}

Zika virus is an emerging flavivirus that has become endemic in the Americas, having been recently documented in multiple countries across Central and South America. It should now be considered in all cases of returning travellers with fever and rash from these areas. Clinical presentation of Zika viral infection is similar to other medically important arboviruses including dengue and chikungunya virus. Measles can also have a similar presentation, posing additional challenges due to infection control implications. Serologic diagnosis is challenging given the cross-reaction with other flaviviruses, as well as the significant time delay in obtaining results. Prompt diagnosis is needed, as the differential diagnosis of fever and rash is broad in a returning traveller, and this would help to avoid unnecessary treatment or investigations. Molecular testing, with PCR and sequencing of the NS5 flavivirus gene, shows promise as a rapid and accurate diagnostic test for Zika virus, as well as for other flaviviruses. Given the possible association between Zika virus and microcephaly, pregnant women and women who could become pregnant should be counselled about this risk prior to travel to areas with documented Zika virus transmission. All travellers to these areas should be counselled on strategies to reduce exposure to mosquito vectors.

\section{Acknowledgements}

We gratefully acknowledge the assistance provided in this case by Stephanie Man, Dr. Patrick Doyle and the BC Centre for Disease Control as well as the National Microbiology Laboratory.

\section{Conflict of interest}

None.

\section{Funding}

None.

\section{References}

1. Kuno G, Chang GJ, Tsuchiya KR, Karabatsos N, Cropp CB. Phylogeny of the genus Flavivirus. J Virology. 1998;72:73-83.

2. Dick GW, Kitchen SF, Haddow AJ. Zika virus I. Isolations and serological specificity. Trans R Soc Trop Med Hyg. 1952;46(5): 509-20.

3. Robin Y, Mouchet J. Serological and entomological study on yellow fever in Sierra Leone. Bull Soc Patho Exot Filiales. 1975;68:249-58.

4. Monlun E, Zeller H, Le Guenno B, Traore-Lamizana M, Hervy JP, Adam F, et al. Surveillance of the circulation of arbovirus of medical interest in the region of eastern Senegal. Bull Soc Pathol Exot. 1993;86(1):21-8.

5. Jan C, Languillat G, Renaudet J, Robin Y. A serological survey of arboviruses in Gabon. Bull Soc Path Exot Filiales. 1978;71:140-6.

6. Fagbami AH. Zika virus infections in Nigeria: virological and seroepidemiological investigations in Oyo State. J Hyg (Lond). 1979;83:213-9

7. Pond WL. Arthropod-borne virus antibodies in sera from residents of South-East Asia. Trans R Soc Trop Med Hyg. 1963;57:364-71.

8. Olson JG, Ksiazek TG, Suhandiman, Triwibowo. Zika virus, a cause of fever in Central Java, Indonesia. Trans R Soc Trop Med Hyg. 1981;75:140-6.

9. Smithburn KC. Neutralizing antibodies against arthopodborne viruses in the sera of long-time residents of Malaya and Borneo. Am J Hyg. 1954;59:157-63.

10. Hayes EB. Zika virus outside Africa. Emerg Infect Dis. 2009;15(9):1347-50

11. Boorman JP, Porterfield JS. A simple technique for infection of mosquitoes with viruses; transmission of Zika virus. Trans R Soc Trop Med Hyg. 1956;50:238-42.

12. Duffy MR, Chen TH, Hancock WT, Powers AM, Kool JL, Lanciotti RS, et al. Zika virus outbreak on Yap Island, Federated States of Micronesia. N Engl J Med. 2009;360(24):2536-43.

13. loos S, Mallet HP, Leparc Goffart I, Gauthier V, Cardoso T, Herida M. Current Zika virus epidemiology and recent epidemics. Med Mal Infect. 2014(44):302-7.

14. Cardoso CW, Paploski IA, Kikuti M, Rodrigues MS, Silva MM, Campos GS, et al. Outbreak of exanthematous illness associated with Zika, Chikungunya, and Dengue viruses, Salvador, Brazil. Emerg Infect Dis. 2015;21(12):2274-6.

15. Zancluca C, de Melo VC, Mosimann AL, Dos Santos GI, Dos Santos CN, Luz K. First report of autochthonous transmission of Zika virus in Brazil. Mem Inst Oswaldo Cruz. 2015;110(4):569-72.

16. ProMED-mail. Zika virus - Americas. ProMED-mail 2015 Dec 5. Archive Number: 20151205.3842908. http://www.promedmail.org. 
17. Patel P, Landt $O$, Kaiser M, Faye $O$, Koppe $T$, Lass $U$, et al. Development of one-step quantitative reverse transcription PCR for the rapid detection of Flavivirus. Virol J. 2013; 10: 58.

18. Staples JE, Fischer M. Chikungunya virus in the Americas - what a vectorborne pathogen can do. N Engl J Med. 2014;371:887-9.

19. Musso D. Cao Lormeau VM, Gubler DJ. Zika virus: following the path of dengue and chikungunya? Lancet. 2015;386(9990):243-4.

20. European Centre for Disease Prevention and Control. Rapid risk assessment: microcephaly in Brazil potentially linked to the Zika virus epidemic. Stockholm (SE): ECDC; 2015 Nov 24

21. Fonseca K, Meatherall B, Zarra D, Drebot M, MacDonald J, Papparaju K, et al. First case of Zika virus infection in a returning Canadian traveler. Am J Trop Med Hyg. 2014;91(5):1035-8.
22. Lanciotti RS, Kosoy OL, Laven JJ, Velez JO, Lambert AJ, Johnson AJ et al. Genetic and serologic properties of Zika virus associated with an epidemic, Yap State, Micronesia, 2007. Emerg Infect Dis. 2008;14(8):1232-9.

23. Centers for Disease Control and Prevention. Zika virus. For health care providers: diagnostic testing. Atlanta (GA): CDC. http://www.cdc.gov/zika/hc-providers/diagnostic.html/

24. Gourinat AC, O'Connor O, Calvez E, Goarant C, DupontRouzeyrol M. Detection of Zika virus in urine. Emerg Infect Dis. $2015 ; 21(1): 84-6$.

25. Leung GH, Baird RW, Druce J, Anstley NM. Zika virus infection in Australia following a monkey bite in Indonesia. Southeast Asian J Trop Med Public Health. 2015;46(3):460-4. 